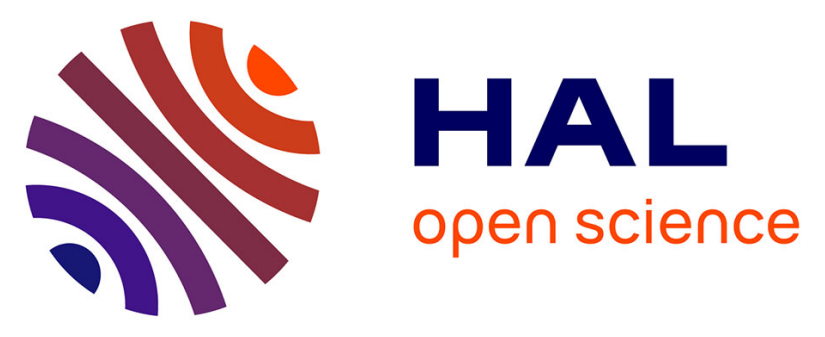

\title{
Impact of cyclosporine A concentration on acute graft-vs-host disease incidence after haploidentical hematopoietic cell transplantation
}

Nicolas Stocker, Remy Dulery, Giorgia Battipaglia, Eolia Brissot, Clémence Mediavilla, Simona Sestili, Annalisa Paviglianiti, Tounes Ledraa, Razan Mohty, Abdulhamid Bazarbachi, et al.

\section{To cite this version:}

Nicolas Stocker, Remy Dulery, Giorgia Battipaglia, Eolia Brissot, Clémence Mediavilla, et al.. Impact of cyclosporine A concentration on acute graft-vs-host disease incidence after haploidentical hematopoietic cell transplantation. European Journal of Haematology, 2019, 103 (1), pp.10-17. 10.1111/ejh.13233 . hal-02339583

\section{HAL Id: hal-02339583 \\ https://hal.sorbonne-universite.fr/hal-02339583}

Submitted on 30 Oct 2019

HAL is a multi-disciplinary open access archive for the deposit and dissemination of scientific research documents, whether they are published or not. The documents may come from teaching and research institutions in France or abroad, or from public or private research centers.
L'archive ouverte pluridisciplinaire HAL, est destinée au dépôt et à la diffusion de documents scientifiques de niveau recherche, publiés ou non, émanant des établissements d'enseignement et de recherche français ou étrangers, des laboratoires publics ou privés. 
1 Impact of Cyclosporine-A Concentration on Acute Graft-versus-Host Disease Incidence

2 after Haploidentical Hematopoietic Cell Transplantation

3

4

5 Nicolas Stocker ${ }^{1}$, Remy Duléry ${ }^{2}$, Giorgia Battipaglia 2, Eolia Brissot ${ }^{1,2}$, Clémence

6 Médiavilla ${ }^{1,2}$, Simona Sestili ${ }^{2}$, Annalisa Paviglianiti ${ }^{2}$, Tounes Ledraa ${ }^{1,2}$, Razan Mohty ${ }^{2}$,

7 Abdulhamid Bazarbachi ${ }^{2}$, Ramdane Belhocine ${ }^{2}$, Anne Vekhoff ${ }^{2}$, Annalisa Ruggeri ${ }^{2}$,

8 Mohamad Mohty ${ }^{1,2}$, Florent Malard ${ }^{1,2}$.

9

10

11 France

12

13

14 Running title: Role of cyclosporine-A in Haplo-HCT

15

16 Corresponding Author:

17 Florent Malard MD, PhD

18 Service d'Hématologie Clinique, Hôpital Saint-Antoine, AP-HP

19184 rue du Faubourg Saint-Antoine, F-75012, Paris, France

20 Tel : +331492826 24; Fax : +33149283375

21 Mail : florent.malard@inserm.fr

22

23 Competing interest statement: The authors declare no competing financial interests.

24 Abstract word count: 199

25 Manuscript word count: 2649

26 Reference count: 22

27 Number of tables: 3

28 Number of figures: 3 


\section{Abstract}

Objectives: This retrospective study analyzed the impact of early cyclosporine-A (CsA) initiation (day - 3) on the risk of acute graft-versus-host disease (aGvHD) after haploidentical hematopoietic cell transplantation (Haplo-HCT) using post-transplant cyclophosphamide Methods: Sixty-one consecutives patients who underwent Haplo-HCT were analyzed.

Results: At day +180 , the cumulative incidences of grade II-IV and grade III-IV aGvHD were $39 \%$ and $18 \%$, respectively. Patients having a lowest CsA concentration $(<301 \mathrm{ng} / \mathrm{mL}$; the cut-off value used to segregate the patients between low and high CsA concentrations) in the first week after Haplo-HCT had a significantly higher risk of grade II-IV aGvHD $(P=.02)$, severe grade III-IV aGvHD (P=.03), cGvHD $(P=.02)$ and extensive cGvHD $(P=.04)$. In multivariate analysis, a higher CsA concentration $(\geq 301 \mathrm{ng} / \mathrm{mL})$ during the first week following Haplo-HCT was the only parameter significantly associated with a reduced risk of grade II-IV and grade III-IV aGvHD (RR=.21; $\mathrm{P}=.049$ and $\mathrm{RR}<0.001 ; \mathrm{P}<.0001$, respectively). We find no correlation between CSA concentration and relapse, non-relapse mortality, progression free survival, GvHD-free and progression free survival or overall survival.

Conclusions: CsA could be initiated early before Haplo-HCT with achievement of high CsA concentration to reduce the risk of aGvHD without any detrimental effect on relapse.

Key words:

- Cyclosprorine-A

- Haploidentical stem cell transplantation

- Post-transplant cyclophosphamide

- Acute graft-versus-host disease. 


\section{Introduction}

Allogeneic hematopoietic stem cell transplantation using a related haploidentical donor (Haplo-HCT) is an alternative option for patients lacking a fully matched sibling or a well matched unrelated donor ${ }^{1}$. However, Haplo-HCT is limited by the immunologic recognition and destruction of host tissues due to the number of HLA mismatches and termed graftversus-host disease (GvHD). Therefore, both in its acute and chronic forms (GvHD is one the main life-threatening complications after Haplo-HCT ${ }^{2}$. However, new strategies have been developed for GvHD prophylaxis post Haplo-HCT, such as the use of high dose antithymocyte globulin (ATG) - the so called GIAC protocol - or the use of post-transplant highdose cyclophosphamide (PTCy) ${ }^{3}$. In particular the use of high-dose PTCy $(50 \mathrm{mg} / \mathrm{kg}$ days +3 and +4 ) has been developed as an effective GvHD prophylaxis by Luznik et al. ${ }^{4}$, based on the rationale that cyclophosphamide is non-toxic to hematopoietic stem cells and can selectively deplete the alloreactive T cells. In this first report, PTCy was combined with mycophenolate mofetil (MMF) and tacrolimus, which were initiated after completion of PTCy to avoid blocking Cy-induced tolerance ${ }^{4,5}$. Bacigalupo et al. slightly modified the GvHD prophylaxis with PTCy $(50 \mathrm{mg} / \mathrm{kg}$ days +3 and +5$)$ together with CsA and MMF started at day 0 and day +1 respectively, resulting in a $4 \%$ incidence of grade III-IV acute GvHD (aGvHD) with bonemarrow (BM) grafts ${ }^{6}$. However, use of peripheral blood stem cells grafts (PBSC) in the PTCy setting is associated with an increased risk of aGvHD compared to $\mathrm{BM}$ grafts ${ }^{7}$ highlighting the need to reinforce GvHD prophylaxis in those patients. Therefore, in our center when using PBSC grafts for Haplo-HCT with PTCy, we decided to incorporate a low dose of ATG in the conditioning regimen and initiated CsA earlier at day -3 before transplant, to lower the risk of GvHD associated with PBSC 7 . 
81 The importance of achieving a high CsA concentration early after transplant to lower the

82 incidence of aGvHD has been clearly demonstrated ${ }^{8-11}$. However, all the studies have been

83 performed outside of the Haplo-HCT setting and the exact role of an early high CsA 84 concentration on aGvHD remains to be determined. Furthermore, whether to start CsA 85 before or after PTCy still remains controversial. Thus, while it was thought that 86 administration of a calcineurin inhibitor before PTCy could interfere with Cy induced 87 tolerance, initiation of CSA before PTCy has been reported to be associated with a very low 88 incidence of aGvHD without suppressing the PTCy effect ${ }^{6}$.

89 With this background, we decided to retrospectively analyze 61 consecutive patients who 90 underwent Haplo-HCT with PBSC grafts and PTCy with the aim of assessing the impact of 91 early initiation of CSA (before PTCy), and the correlation between early CsA concentration 92 and the onset of aGvHD. 


\section{Patients and Methods}

\section{Patients}

98 Sixty-one patients who underwent Haplo-HCT for hematological malignancies between 99 October 2013 and August 2017 at the University Hospital of Saint-Antoine (AP-HP, Paris,

100 France) were included in this retrospective single-center study. The primary endpoint of the 101 study was to determine the impact of the serum CSA concentration on the risk of grade II-IV 102 aGvHD. For the purpose of this analysis, all patients who received Haplo-HCT with PTCy and 103 a PBSC graft were included. Written informed consent was obtained from each patient and

104 donor. This study was approved by the hospital's institutional review board, and the local 105 ethics committee. All patients had no HLA-identical sibling or unrelated donor available or a 106 suitable unrelated donor was not available within the appropriate time frame for the 107 patient's malignancy and clinical circumstances. HLA typing was performed according to the 108 recommendations of the European Federation for Immunogenetics (EFI) Histocompatibility

109 Laboratory standards during the study period. Molecular high-resolution typing of HLA-A, -B, $110-C,-D Q B 1$, and -DRB1 alleles was performed for each patient and donor.

\section{Transplantation Procedure}

112 All patients received the preparative regimen as inpatients in private rooms and remained

113 hospitalized until hematopoietic and clinical recovery. They all received granulocyte-colony

114 stimulating factor mobilized PBSC as grafts and post-transplantation immunosuppression

115 with CsA and MMF. CsA was administered at a dose of $3 \mathrm{mg} / \mathrm{kg}$ by continuous intravenous

116 infusion starting from day -3 and changed to twice daily oral dosing as soon as tolerated.

117 MMF was administered at a fixed oral dose of $2 \mathrm{~g}$ per day starting from day +5 without 
118 adjustment. In the absence of GvHD, MMF and CsA were tapered over 4 weeks starting from

119 day +60 and day +90 , respectively. Of note, supportive care was the same for all patients

120 during the whole study period. CMV infection management was also homogeneous. All

121 blood products were filtered, irradiated and CMV screened. In the first 100 days post Haplo-

$122 \mathrm{HCT}$, patients were assessed at least once per week for CMV reactivation by PCR assay to

123 initiate preemptive ganciclovir therapy.

\section{CsA Concentration Monitoring and Diagnosis of GvHD}

125 CsA blood trough concentrations were monitored 3 times per week during the intravenous

126 treatment and at least once per week after switch to oral dosing. Trough levels of CsA were

127 assessed by radioimmunoassay (RIA) using commercially available kits (Immunotech,

128 Beckman-Coulter, France) according to the manufacturer's procedures. Blood samples were

129 collected early in the morning. For the purpose of this analysis, the mean weekly con-

130 centration of CSA was calculated for each patient using the different concentrations

131 measured during a defined week. CsA doses were adjusted to achieve blood levels of

132 between 200 and $300 \mathrm{ng} / \mathrm{mL}$ and to prevent renal dysfunction. Acute GvHD was diagnosed

133 and graded according to the revised Glucksberg criteria ${ }^{12}$ and chronic GvHD (cGvHD) was

134 diagnosed and graded according to the Seattle standard criteria ${ }^{13}$. Time to neutrophil

135 recovery was defined as the first of 3 consecutive days in which the absolute neutrophil

136 count exceeded $0.5 \times 10^{9} / \mathrm{L}$, and platelet recovery as the first of 5 consecutive days with a

137 platelet count above $50 \times 10^{9} / \mathrm{L}$ without the need for platelet transfusion. 
139 Comparison between or patients who experienced no or grade I acute GvHD and patients

140 with grade II-IV aGvHD was carried out using the chi-squared test for categorical variables,

141 and the t-test for continuous data. The diagnostic values of the CsA concentration were 142 assessed at week 1, 2, 3 and 4 after Haplo-HCT by constructing ROC curves and then for each 143 one, calculating the area under the curve (AUC). The cumulative incidence of aGvHD, cGvHD, 144 relapse, and non-relapse mortality (NRM) were estimated and groups were compared using

145 Gray's test. Relapse was defined as a competitive risk for NRM, and vice versa. Progression146 free survival (PFS) was calculated from the date of Haplo-HCT until the time to relapse or 147 progression. Overall survival (OS) was calculated from the date of Haplo-HCT until the time 148 of death or the last observation if a patient remained alive. Refined GvHD-free and 149 progression-free survival (GPFS) was defined as a combination of survival with no evidence 150 of relapse/progression, grade III to IV aGvHD, and extensive cGvHD ${ }^{14}$. Probabilities of PFS, 151 GPFS and OS were estimated using the Kaplan-Meier method and groups were compared 152 using the Log-rank test. Fine-Gray logistic regression analyses were performed with relevant 153 variables to identify independent risk factors for grade II-IV aGvHD, grade III-IV aGvHD, 154 cGvHD and extensive cGvHD development. All statistical analyses were performed using EZR version 1.37 (Saitama Medical Center, Jichi Medical University, Japan), which is a graphical user interface for R (The R Foundation for Statistical Computing; version 3.5.0) ${ }^{15}$. 


\section{Results}

\section{Characteristics of Patients, Donors and Transplantations}

163 Patient, donor, and transplant characteristics are summarized in Table 1 . The median age 164 was 53 years (range, 15-72), with 16 male patients (26\%) receiving a graft from a female

165 donor. Diagnoses were myeloid malignancies (64 \%) or lymphoid malignancies (36\%).

166 According to the Disease Risk Index, patients were considered as low-risk, intermediate-risk,

167 high-risk or very-high-risk (8\%, 56\%, 31\% and 5\% respectively) ${ }^{16}$. Twenty-five patients (41\%)

168 with refractory disease received a sequential conditioning regimen based on thiotepa 5 to 10

$169 \mathrm{mg} / \mathrm{kg}$, etoposide $400 \mathrm{mg} / \mathrm{m}^{2}$, and cyclophosphamide $1600 \mathrm{mg} / \mathrm{m}^{2}$ between days -15 to -9 ,

170 followed by, after a 3-day rest, reduced intensity conditioning (RIC) with fludarabine 150

$171 \mathrm{mg} / \mathrm{m}^{2}$ and i.v. busulfan $6.4 \mathrm{mg} / \mathrm{kg}$ on days -6 to $-1{ }^{17}$, while the remaining 36 patients (59\%)

172 received a reduced-intensity/toxicity conditioning (RIC/RTC) regimen based on $150 \mathrm{mg} / \mathrm{m}^{2}$

173 fludarabine, 2 to 3 days of $3.2 \mathrm{mg} / \mathrm{kg} / \mathrm{d}$ busulfan and thiotepa. Fifty-one patients (83\%)

174 received ATG as part of the conditioning regimen. All patients received standard PTCy, 9

$175(15 \%)$ at day +3 and $52(85 \%)$ at day +3 and day +5 . Median follow-up among surviving

176 patients was 21 months (range, 13-53) (Table 2).

\section{CsA Concentration and aGvHD}

179

180 Median concentrations of CsA in the blood at 1, 2, 3, and 4 weeks after Haplo-HCT were 272

$181 \mathrm{ng} / \mathrm{mL}$ (range, 114-911), $296 \mathrm{ng} / \mathrm{mL}$ (range, 132-516), $251 \mathrm{ng} / \mathrm{mL}$ (range, 111-485), and 246

$182 \mathrm{ng} / \mathrm{mL}$ (range, 36-375), respectively (Figure 1). ROC curve analysis revealed that CsA

183 concentration was an accurate discriminator of the risk of grade II-IV aGvHD. The cut-off

184 values providing the best balance between sensitivity and specificity were $301 \mathrm{ng} / \mathrm{ml}$, 

day +180 , the cumulative incidences of grade II-IV and grade III-IV aGvHD were $39 \%$ and

$18718 \%$, respectively. Univariate analysis of risk factors for grade II-IV aGvHD is shown in Table

188 1. Patients having the lowest CsA concentration in the first week after Haplo-HCT had a 189 significantly higher risk of grade II-IV aGvHD $(\mathrm{P}=.02)$ (Table 2, Figure 2A). Moreover, there was a significant association between severe grade III-IV aGvHD and CsA concentration in

191 the first week after Haplo-HCT $(\mathrm{P}=.03)$ (Table 2, Figure 2B). In contrast, we did not find any correlation between CSA concentration beyond the first week and the risk of aGvHD. In

193 multivariate logistic regression analyses (Table 3), a higher CsA concentration ( $\geq 301 \mathrm{ng} / \mathrm{mL}$;

194 the cut-off value used to segregate the patients between low and high CsA concentrations) 195 during the first week following Haplo-HCT was the only independent parameter significantly 196 associated with a reduced risk of grade II-IV and grade III-IV aGvHD (RR .21; 95\% Cl, 0.050.99, $\mathrm{P}=.049 ;$ and $\mathrm{RR}<.001 ; 95 \% \mathrm{Cl}, 0.000007-0.00005, \mathrm{P}<.0001$, respectively).

200 Engraftment and clinical outcome characteristics for the whole cohort and according to the 201 CsA level in the first week are summarized in Table 2. Median time for neutrophil and 202 platelet engraftment) was 18 days (range, 13 to 35 ) and 26 days (range, 14 to 88 ), 203 respectively. Three secondary graft failures occurred after Haplo-HCT. The cumulative 204 incidence (CI) of cGvHD, extensive cGvHD and relapse was 41\%, 19\% and 35\% at 18 months 205 after Haplo-HCT, respectively. At 18 months after the transplant, the OS, PFS and GPFS rates were $60 \%, 55 \%$ and $48 \%$ respectively. Patients having the lowest CsA concentration in the 207 first week after Haplo-HCT had a significantly higher risk of cGvHD $(P=.02)$ and of extensive 
208 cGvHD (P= .04). In multivariate logistic regression analysis, no parameters were associated 209 with an increased risk of cGVHD (Table 3).

210 We find no statistically significant correlation in terms of relapse incidence, NRM, PFS, GPFS

211 or OS between patients having the highest CSA concentration in the first week after Haplo-

$212 \mathrm{HCT}$, compared to patients with a lower CsA concentration (Figure 3).

213

214

215

216

217

218

219

220

221

222

223

224

225

226

227

228 
230 Thirty years ago, the Seattle group demonstrated that a low CsA concentration increases the

231 risk of aGvHD, and that concentrations should be monitored in BM transplant recipients ${ }^{8}$. In 232 this study, Yee et al. reported a relative risk of 0.7 for every increase of $100 \mathrm{ng} / \mathrm{mL}$ of the CsA 233 concentration ${ }^{8}$. This inverse relation between trough CsA levels and incidence of GvHD in 234 patients that received a bone marrow graft was further confirmed in the early 1990 s $11,18,19$. 235 Our group found a similar correlation in patients transplanted from matched related or 236 unrelated donors and PBSC graft ${ }^{11}$. However, data regarding the impact of CsA level on 237 GvHD in the Haplo-HCT setting are scarce. In our study, we evaluated the impact of serum 238 CsA concentration on the incidence of aGvHD in a homogenous group of adult patients 239 undergoing Haplo-HCT with PBSC and PTCy as GvHD prophylaxis given in combination with 240 ATG, CsA and MMF.

241 Due to the mechanism by which PTCy aids in preventing GvHD after Haplo-HCT, which 242 involves in vivo selective destruction of alloreactive T cells, induction of tolerance, and intra243 thymic clonal deletion of alloreactive T lymphocytes ${ }^{20}$, it was thought that early initiation of 244 CsA before Haplo-HCT would abolish the PTCy effect. Our strategy was associated with day $245+180$ cumulative incidences of grade II-IV and grade III-IV aGvHD of $39 \%$ and $18 \%$, 246 respectively. These findings are comparable with the incidences found by Ruggeri et al. ${ }^{7}$ 247 (38\% and 14\%, respectively) and Castagna et al. ${ }^{21}$ ( $38 \%$ and $12 \%$, respectively) in patients 248 receiving PBSC Haplo-HCT with PTCy and calcineurin inhibitor initiation at day +5 . Therefore, 249 early introduction of CSA is not detrimental ${ }^{21}$. On the contrary, ${ }^{8-11}$, we observed that 250 achievement of a high concentration of CsA at time of engraftment, before PTCy 251 administration, was associated with a lower incidence of aGVHD, being $18 \%$ for grade II-IV 
252 and $0 \%$ for grade III-IV, at day +180 . These findings were also observed in the setting of 253 allogeneic hematopoietic stem cell transplantation using a well matched-related or 254 matched-unrelated donors ${ }^{8,11}$.

255 In addition, we find that an achievement of a high CsA concentration during the first week 256 after transplant, resulted in a significant decrease of the $\mathrm{Cl}$ of cGvHD and extensive cGvHD, 257 with a $\mathrm{Cl}$ at 18 months of $16 \%$ and $0 \%$ respectively. This result compares very favorably with 258 the study by Ruggeri et al. that reported a $\mathrm{Cl}$ of $32 \%$ and $10 \%$ respectively.

259 One could question the impact of achievement of a high CsA concentration on the risk of 260 relapse. However, in univariate analysis, we did not find any impact on the $\mathrm{Cl}$ of relapse. 261 Another concern may be the deleterious impact of a high CsA concentration on renal 262 function. Given the retrospective nature of this study, we were not able to analyze renal 263 function, however we do not report any long-term renal side effect in the high CsA 264 concentration group of patients.

265 Besides PTCy, the impact of early CsA concentration was recently investigated in the context 266 of T-cell replete Haplo-HCT using the GIAC protocol ${ }^{22}$. Similar to our findings, the authors 267 report that achievement of a high CsA concentration after haplo-HCT was associated with a 268 reduced incidence of aGvHD ${ }^{22}$.

269 While our study may underestimate unmeasured factors that have not been considered, a 270 limitation when conducting retrospective studies, we find that early introduction and 271 monitoring of CSA in Haplo-HCT with PTCy GVHD prophylaxis can improve the clinical 272 outcome by reducing the risk of grade II-IV and grade III-IV aGvHD in patients receiving PBSC 273 grafts. Although one must acknowledge that clinical obstacles such as renal failure, drug 
274 interactions, and pharmacodynamics of CsA may preclude early achievement of high CsA

275 levels, we conclude that data from the current study indicate that CsA should be initiated

276 before PTCy with the aim of achieving a high CSA trough blood concentration during the

277 early post-Haplo-HCT to prevent the onset of aGvHD. Inadequate or insufficient early

278 exposures to CsA following Haplo-HCT with PTCy GvHD prophylaxis can be a serious risk for

279 developing severe aGvHD and a high CsA target concentration remains an effective tool to

280 prevent the onset of this event. 


\section{Acknowledgements}

283 The authors acknowledge the Association for Training, Education and Research in

284 Hematology, Immunology and Transplantation for the generous and continuous support to 285 this research work. The authors also thank the clinical teams who provided care for the 286 study patients and for their dedication to this study.

288 Authorship Contributions

289 NS, MM and FM designed the study, NS collected the data, EB, GB, RD, FG, AR, MM and FM

290 recruited the patients, NS and FM performed the statistical analysis and, NS, MM and FM

291 prepared the manuscript for publication. All authors analyzed the data, reviewed the 292 manuscript, and agreed to its submission for publication.

294 Conflict-of-interest disclosure

295 The authors declare no competing financial interests. 
1. Passweg JR, Baldomero H, Bader P, et al. Hematopoietic SCT in Europe 2013: recent trends in the use of alternative donors showing more haploidentical donors but fewer cord blood transplants. Bone Marrow Transplant. 2015;50(4):476-482.

2. Mohty M, Gaugler B. Inflammatory cytokines and dendritic cells in acute graftversus-host disease after allogeneic stem cell transplantation. Cytokine Growth Factor Rev. 2008;19(1):53-63.

3. Kanakry CG, Fuchs EJ, Luznik L. Modern approaches to HLA-haploidentical blood or marrow transplantation. Nat Rev Clin Oncol. 2016;13(1):10-24.

4. Luznik L, O'Donnell PV, Symons HJ, et al. HLA-haploidentical bone marrow transplantation for hematologic malignancies using nonmyeloablative conditioning and high-dose, posttransplantation cyclophosphamide. Biol Blood Marrow Transplant. 2008;14(6):641-650.

5. Nomoto K, Eto M, Yanaga K, Nishimura Y, Maeda T, Nomoto K. Interference with cyclophosphamide-induced skin allograft tolerance by cyclosporin A. J Immunol. 1992;149(8):2668-2674.

6. Bacigalupo A, Dominietto A, Ghiso A, et al. Unmanipulated haploidentical bone marrow transplantation and post-transplant cyclophosphamide for hematologic malignanices following a myeloablative conditioning: an update. Bone Marrow Transplant. 2015;50 Suppl 2:S37-39.

7. Ruggeri A, Labopin M, Bacigalupo A, et al. Bone marrow versus mobilized peripheral blood stem cells in haploidentical transplants using posttransplantation cyclophosphamide. Cancer. 2018;124(7):1428-1437.

8. Yee GC, Self SG, McGuire TR, Carlin J, Sanders JE, Deeg HJ. Serum cyclosporine concentration and risk of acute graft-versus-host disease after allogeneic marrow transplantation. N Engl J Med. 1988;319(2):65-70.

9. Martin P, Bleyzac N, Souillet G, et al. Clinical and pharmacological risk factors for acute graft-versus-host disease after paediatric bone marrow transplantation from matched-sibling or unrelated donors. Bone Marrow Transplant. 2003;32(9):881-887.

10. Martin P, Bleyzac N, Souillet G, et al. Relationship between CsA trough blood concentration and severity of acute graft-versus-host disease after paediatric stem cell transplantation from matched-sibling or unrelated donors. Bone Marrow Transplant. 2003;32(8):777-784.

11. Malard F, Szydlo RM, Brissot E, et al. Impact of cyclosporine-A concentration on the incidence of severe acute graft-versus-host disease after allogeneic stem cell transplantation. Biol Blood Marrow Transplant. 2010;16(1):28-34.

12. Przepiorka D, Weisdorf D, Martin P, et al. 1994 Consensus Conference on Acute GVHD Grading. Bone Marrow Transplant. 1995;15(6):825-828.

13. Shulman HM, Sullivan KM, Weiden PL, et al. Chronic graft-versus-host syndrome in man. A long-term clinicopathologic study of 20 Seattle patients. Am J Med. 1980;69(2):204-217.

14. Ruggeri A, Labopin M, Ciceri F, Mohty M, Nagler A. Definition of GvHD-free, relapse-free survival for registry-based studies: an ALWP-EBMT analysis on patients with AML in remission. Bone Marrow Transplant. 2016;51(4):610-611.

15. Kanda Y. Investigation of the freely available easy-to-use software 'EZR' for medical statistics. Bone Marrow Transplant. 2013;48(3):452-458.

16. Armand P, Kim HT, Logan BR, et al. Validation and refinement of the Disease Risk Index for allogeneic stem cell transplantation. Blood. 2014;123(23):3664-3671. 
17. Dulery R, Menard AL, Chantepie S, et al. Sequential Conditioning with Thiotepa in T Cell- Replete Hematopoietic Stem Cell Transplantation for the Treatment of Refractory Hematologic Malignancies: Comparison with Matched Related, HaploMismatched, and Unrelated Donors. Biol Blood Marrow Transplant. 2018.

18. Przepiorka D, Shapiro S, Schwinghammer TL, et al. Cyclosporine and methylprednisolone after allogeneic marrow transplantation: association between low cyclosporine concentration and risk of acute graft-versus-host disease. Bone Marrow Transplant. 1991;7(6):461-465.

19. Ghalie R, Fitzsimmons WE, Weinstein A, Manson S, Kaizer H. Cyclosporine monitoring improves graft-versus-host disease prophylaxis after bone marrow transplantation. Ann Pharmacother. 1994;28(3):379-383.

20. Luznik L, O'Donnell PV, Fuchs EJ. Post-transplantation cyclophosphamide for tolerance induction in HLA-haploidentical bone marrow transplantation. Semin Oncol. 2012;39(6):683-693.

21. Castagna L, Bramanti S, Furst S, et al. Tacrolimus compared with cyclosporine A after haploidentical T-cell replete transplantation with post-infusion cyclophosphamide. Bone Marrow Transplant. 2016;51(3):462-465.

22. Yang X, Yang S, Sun A, et al. Impact of cyclosporine-A concentration in T-cell replete haploidentical allogeneic stem cell transplantation. Clin Transplant. 2018;32(4):e13220. 


\begin{tabular}{|c|c|c|c|}
\hline Characteristic & $\begin{array}{l}\text { Patients with no or } \\
\text { Grade I aGvHD } \\
\text { n=43; (\%) }\end{array}$ & $\begin{array}{l}\text { Patients with Grade } \\
\text { II-IV aGvHD } \\
\text { n=18; (\%) }\end{array}$ & $\begin{array}{c}P \\
\text { value }\end{array}$ \\
\hline Patient age, (yrs) median (range) & $54(15-72)$ & $49(16-66)$ & .14 \\
\hline Patient age $>60$ yrs & $15(35)$ & $4(22)$ & .38 \\
\hline \multicolumn{4}{|l|}{ Patient gender } \\
\hline Male & $28(65)$ & $11(61)$ & .77 \\
\hline Female & $15(35)$ & $7(39)$ & \\
\hline \multicolumn{4}{|l|}{ Donor gender } \\
\hline Female to male & $11(26)$ & $5(28)$ & 1 \\
\hline ABO mismatch & $24(56)$ & $7(39)$ & .27 \\
\hline \multicolumn{4}{|l|}{ CMV serologic status } \\
\hline Seronegative donor-recipient pair & $3(7)$ & $3(17)$ & .34 \\
\hline \multicolumn{4}{|l|}{ Diagnosis } \\
\hline Myeloid malignancies & $28(65)$ & $11(61)$ & .77 \\
\hline Lymphoid malignancies & $15(35)$ & $7(39)$ & \\
\hline \multicolumn{4}{|l|}{ Disease Risk Index } \\
\hline Low-Intermediate & $27(63)$ & $12(67)$ & 1 \\
\hline High-Very High & $16(37)$ & $6(33)$ & \\
\hline \multicolumn{4}{|l|}{ Conditioning regimen category } \\
\hline $\mathrm{RIC} / \mathrm{RTC}$ & $25(58)$ & $11(61)$ & 1 \\
\hline Sequential conditioning & $18(42)$ & $7(39)$ & \\
\hline \multicolumn{4}{|l|}{ 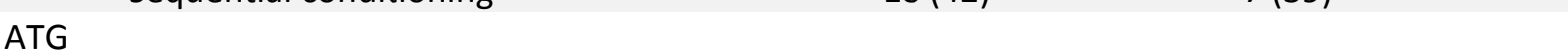 } \\
\hline Without & $5(12)$ & $5(28)$ & .14 \\
\hline With & $38(88)$ & $13(72)$ & \\
\hline \multicolumn{4}{|l|}{ Post-transplant cyclophosphamide } \\
\hline$D+3$ & $8(19)$ & $1(6)$ & .25 \\
\hline$D+3 / D+5$ & $35(81)$ & $17(94)$ & \\
\hline \multicolumn{4}{|c|}{$\begin{array}{l}\text { CsA blood concentrations during the first week } \\
\text { after Haplo-HCT, median ( } \mathrm{ng} / \mathrm{ml} \text {; range) }\end{array}$} \\
\hline$<301 \mathrm{ng} / \mathrm{ml}$ & $25(58)$ & $16(89)$ & .03 \\
\hline$\geq 301 \mathrm{ng} / \mathrm{ml}$ & $18(42)$ & $2(11)$ & \\
\hline \multicolumn{4}{|c|}{$\begin{array}{l}\text { CSA blood concentrations during the second } \\
\text { week after Haplo-HCT, median ( } \mathrm{ng} / \mathrm{ml} \text {; range) }\end{array}$} \\
\hline$<297 \mathrm{ng} / \mathrm{ml}$ & $23(54)$ & $8(44)$ & .58 \\
\hline$\geq 297 \mathrm{ng} / \mathrm{ml}$ & $20(46)$ & $10(56)$ & \\
\hline \multicolumn{4}{|c|}{$\begin{array}{l}\text { CsA blood concentrations during the third } \\
\text { week after Haplo-HCT, median ( } \mathrm{ng} / \mathrm{ml} \text {; range) }\end{array}$} \\
\hline$<261 \mathrm{ng} / \mathrm{ml}$ & $25(58)$ & $9(50)$ & .59 \\
\hline$\geq 261 \mathrm{ng} / \mathrm{ml}$ & $18(42)$ & $9(50)$ & \\
\hline \multicolumn{4}{|c|}{$\begin{array}{l}\text { CSA blood concentrations during the fourth } \\
\text { week after Haplo-HCT, median ( } \mathrm{ng} / \mathrm{ml} \text {; range) }\end{array}$} \\
\hline$<238 \mathrm{ng} / \mathrm{ml}$ & $20(46)$ & $10(56)$ & .58 \\
\hline$\geq 238 \mathrm{ng} / \mathrm{ml}$ & $23(54)$ & $8(44)$ & \\
\hline
\end{tabular}


Table 2. Engraftment and clinical outcomes after Haplo-HCT

\begin{tabular}{|c|c|c|c|c|}
\hline Characteristic & $\begin{array}{l}\text { All patients } \\
\qquad(\mathrm{n}=61)\end{array}$ & $\begin{array}{c}\text { CsA }<301 \\
n g / m l \\
(n=41)\end{array}$ & $\begin{array}{c}C s A \geq 301 \\
n g / m l \\
(n=20)\end{array}$ & $P$ value \\
\hline Graft failure & $3(5)$ & $2(5)$ & $1(5)$ & 1 \\
\hline $\begin{array}{l}\text { Median time for neutrophil }>0.5 \times 10^{9} / \mathrm{L} \\
\text { (range), days }\end{array}$ & $18(13-35)$ & $17(13-31)$ & $18(13-35)$ & .66 \\
\hline $\begin{array}{l}\text { Median time for platelets }>50 \times 10^{9} / \mathrm{L} \\
\text { (range), days }\end{array}$ & $26(14-88)$ & $24(12-88)$ & $29(13-55)$ & .71 \\
\hline aGvHD incidence at day $+180, \%(95 \% \mathrm{Cl})$ & $63(47-74)$ & $66(46-78)$ & $59(26-77)$ & .38 \\
\hline Grade II-IV & $39(22-52)$ & $49(27-64)$ & $18(0-39)$ & .02 \\
\hline Grade III-IV & $18(7-31)$ & $26(8-41)$ & 0 & .03 \\
\hline cGvHD incidence at month $18, \%(95 \% \mathrm{Cl})$ & $41(22-56)$ & $55(28-72)$ & $16(0-35)$ & .02 \\
\hline Extensive & $19(1-33)$ & $31(2-52)$ & 0 & .04 \\
\hline $\begin{array}{l}\text { Non-relapse mortality at month } 18, \% \\
(95 \% \mathrm{Cl})\end{array}$ & $20(9-30)$ & $23(8-36)$ & $15(0-29)$ & .50 \\
\hline Relapse incidence at month $18, \%(95 \% \mathrm{Cl})$ & $35(18-48)$ & $32(11-48)$ & $44(9-65)$ & .43 \\
\hline $\begin{array}{l}\text { Progression-free survival at month } 18, \% \\
(95 \% \mathrm{Cl})\end{array}$ & $55(42-67)$ & $53(36-67)$ & $60(35-77)$ & .87 \\
\hline GPFS at month $18, \%(95 \% \mathrm{Cl})$ & $48(34-60)$ & $42(26-57)$ & $60(35-77)$ & .39 \\
\hline Overall survival at month $18, \%(95 \% \mathrm{Cl})$ & $60(46-71)$ & $58(41-72)$ & $64(39-81)$ & .67 \\
\hline Median follow-up, months (range) & $21(10-53)$ & $30(10-53)$ & $19(13-52)$ & .64 \\
\hline
\end{tabular}
disease and progression-free survival; cGvHD, chronic graft-versus-host disease; Haplo-HCT, haploidentical hematopoietic stem cell transplantation. Bold denotes statistical significance. 


\begin{tabular}{|c|c|c|}
\hline Outcome & Hazard ratio $(95 \% \mathrm{Cl})$ & $P$ value \\
\hline \multicolumn{3}{|l|}{ Grade II-IV acute GvHD } \\
\hline Age $>60$ vs $<60$ years & $0.68(0.22-2.05)$ & .49 \\
\hline ATG vs no ATG & $0.36(0.12-1.09)$ & .07 \\
\hline $\mathrm{Cs} A \geq 301 \mathrm{ng} / \mathrm{ml}$ vs CsA $<301 \mathrm{ng} / \mathrm{ml}$ & $0.21(0.05-0.99)$ & .049 \\
\hline CMV donor/recipient negative vs others & $0.98(0.19-4.97)$ & .98 \\
\hline Female donor to male recipient vs others & $0.96(0.31-2.99)$ & .95 \\
\hline \multicolumn{3}{|l|}{ Grade III-IV acute GvHD } \\
\hline Age $>60$ vs $<60$ years & $0.72(0.13-3.99)$ & .70 \\
\hline ATG vs no ATG & $0.25(0.05-1.29)$ & .98 \\
\hline $\mathrm{CsA} \geq 301 \mathrm{ng} / \mathrm{ml}$ vs CsA $<301 \mathrm{ng} / \mathrm{ml}$ & $<0.001(0.000007-0.00005)$ & $<.001$ \\
\hline CMV donor/recipient negative vs others & $1.29(0.15-10.9)$ & .82 \\
\hline Female donor to male recipient vs others & $0.86(0.15-4.92)$ & .87 \\
\hline \multicolumn{3}{|l|}{ Chronic GvHD } \\
\hline Age $>60$ vs $<60$ years & $0.46(0.09-2.36)$ & .35 \\
\hline ATG vs no ATG & $1.93(0.38-9.90)$ & .43 \\
\hline $\mathrm{Cs} A \geq 301 \mathrm{ng} / \mathrm{ml}$ vs CsA $<301 \mathrm{ng} / \mathrm{ml}$ & $0.31(0.07-1.44)$ & .13 \\
\hline CMV donor/recipient negative vs others & $3.52(0.55-22.34)$ & .18 \\
\hline Female donor to male recipient vs others & $2.00(0.79-5.00)$ & .14 \\
\hline \multicolumn{3}{|l|}{ Relapse incidence } \\
\hline Age $>60$ vs $<60$ years & $2.06(0.71-6.05)$ & .18 \\
\hline ATG vs no ATG & $0.28(0.11-0.73)$ & .009 \\
\hline $\mathrm{Cs} A \geq 301 \mathrm{ng} / \mathrm{ml}$ vs CsA $<301 \mathrm{ng} / \mathrm{ml}$ & $1.69(0.65-4.38)$ & .28 \\
\hline RTC vs MAC & $0.74(0.10-5.83)$ & .78 \\
\hline DRI very-high/high vs low/very-low & $6.16(0.72-53.05)$ & .10 \\
\hline
\end{tabular}

Abbreviations: aGvHD, acute graft-versus-host disease; ATG, antithymoglobulin; $\mathrm{Cl}$, confidence interval; $\mathrm{CMV}$, cytomegalovirus; CsA, cyclosporine A; Haplo-HCT, haploidentical hematopoietic stem cell transplantation; MAC, myeloablative conditioning regimen; RTC, reduced-toxicity conditioning regimen. Bold denotes statistical significance. 
391 Box and whisker plots are displayed, showing the minimum, first quartile, median, third 392 quartile, and maximum. CsA, cyclosporine-A; Haplo-HCT, haploidentical hematopoietic stem 393 cell transplantation.

Figure 2. Cumulative incidence of grade II-IV aGvHD and grade III-IV aGvHD according to CsA concentration during the first week after Haplo-HCT. Probability of grade II-IV acute GVHD (2a) and grade III-IV acute GVHD (2b) according to CsA 398 concentration (below or over $301 \mathrm{ng} / \mathrm{ml}$ ) in the first week after Haplo-HCT. aGvHD, acute 399 graft versus host disease; CsA, cyclosporine-A; Haplo-HCT, haploidentical hematopoietic 400 stem cell transplantation.

401

402 Figure 3. Other clinical outcomes according to CsA concentration during the first week 403 after Haplo-HCT.

404 Cumulative incidence of chronic GvHD (3a), relapse (3b) and non-relapse mortality (3c) 405 according to CsA concentration (below or over $301 \mathrm{ng} / \mathrm{ml}$ ) in the first week after Haplo-HCT. 406 Progression-free survival (3d); graft-versus-host-disease and relapse-free survival (3e) and 407 overall survival (3f) according to CsA concentration (below or over $301 \mathrm{ng} / \mathrm{ml}$ ) in the first 408 week after Haplo-HCT. cGvHD; chronic graft-versus-host disease, CsA, cyclosporine A; Haplo409 HCT, haploidentical hematopoietic stem cell transplantation; NRM; non-relapse mortality, 410 PFS, progression-free survival; GPFS, graft-versus-host disease and relapse-free survival; OS, 411 overall survival. 


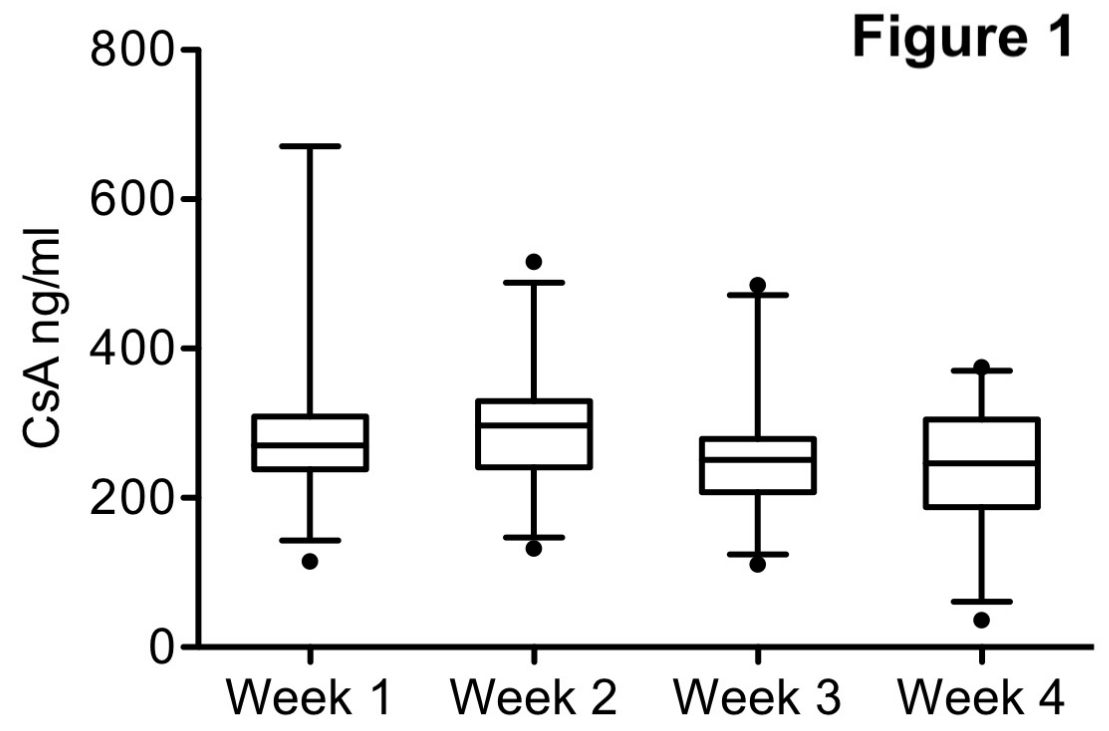

Figure 1

$110 \times 72 \mathrm{~mm}(300 \times 300$ DPI $)$ 


\section{Figure 2}
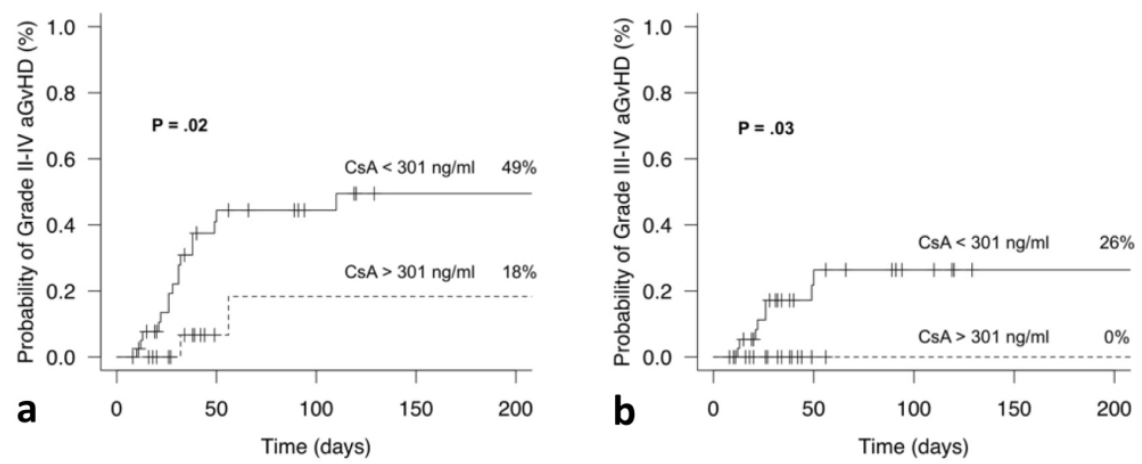

Figure 2

$165 \times 85 \mathrm{~mm}(300 \times 300 \mathrm{DPI})$ 


\section{Figure 3}
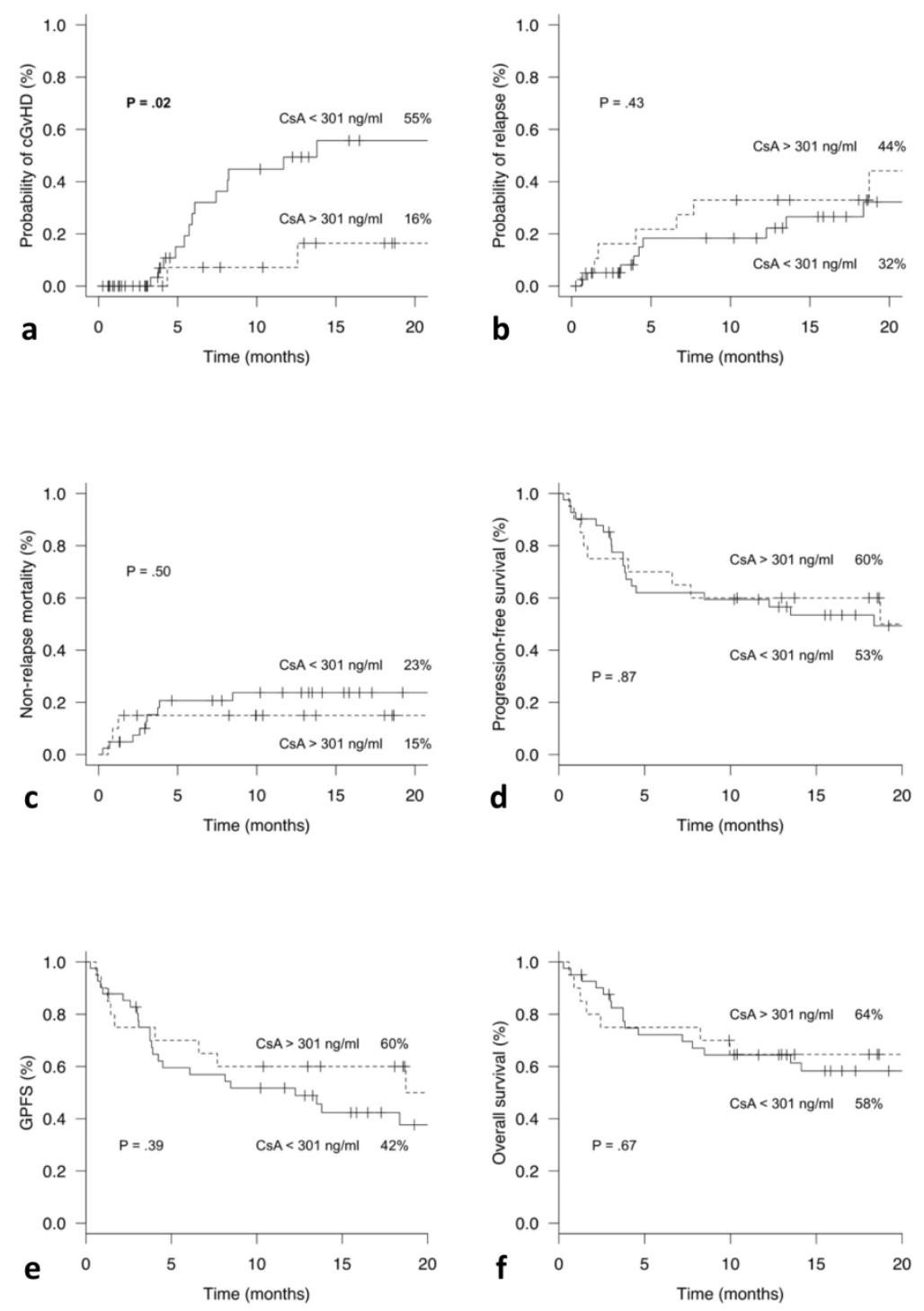

Figure 3

$165 \times 225 \mathrm{~mm}(300 \times 300$ DPI $)$ 